\title{
Intra-amniotic Digoxin for Fetal Anomaly in Second and Early Third Trimester
}

\author{
Shakya B, Chaudhary P, Tumbahangphe M, Jha M \\ Department of Obstetrics and Gynaecology, Paropakar Maternity and Women's Hospital, Thapathali, Kathmandu, Nepal.
}

\begin{abstract}
Aims: Carrying a baby with major anomaly is emotional trauma for mother and her family. If born alive, these babies would either not survive or would have significant disability. The objective of this study was to induce fetal demise by instillation of digoxin intra-amniotically for fetal anomaly before termination of pregnancy.
\end{abstract}

Methods: This was a cross-sectional study undertaken at Paropakar Maternity and Women's Hospital from April 13, 2012 to October 13, 2013. Patient characteristics, gestational age, types of fetal anomaly and its time of detection were recorded in 32 cases with fetal anomaly in second and early third trimester. One milligram digoxin was instilled intra-amniotically under ultrasound guidance and after 24 hours, ultrasonography was done to check fetal cardiac activity. Induction of labour using misoprostol as per FIGO guideline and augmentation with oxytocin was done if already in labour. Induction to delivery interval, effectiveness and side effects of digoxin were recorded.

Results: Among 32 cases of fetal anomaly, majority occurred in primigravida ( $\mathrm{n}=17,53.12 \%$ ). The mean age was 25 years and mean gestational age was 26.5 weeks'. Majority of them were anencephaly $(n=16,50 \%)$ followed by multiple anomaly $(n=6,18.75 \%)$. Thirty one $(96.87 \%)$ cases visited out-patient department, $25 \%$ of them had presented late at 30-34 weeks'. Following 24 hours of intra-amniotic digoxin, cardiac activity was absent in all cases and there was no side effect of digoxin. Spontaneous expulsion occurred in $9.37 \%$, oxytocin augmentation $(n=6,18.75 \%)$ and misoprostol induction $(n=23,71.87 \%)$. The mean induction to delivery interval was 47.3 hours.

Conclusions: Intra-amniotic digoxin instillation appeared safe and effective in inducing fetal demise for fetal anomaly in second and early third trimester.

Keywords: fetal anomaly, fetal demise, intra-amniotic digoxin, second and early third trimester.

\section{INTRODUCTION}

The incidence of fetal anomaly is $2-3 \% .^{1}$ Carrying a baby with major anomaly is emotional trauma for mother and her family. Moreover, managing such cases is dilemma for care provider. Medical termination of such pregnancy is legal and cost effective. However, fetal survival after induced abortion for such major anomalies is stressful situation for mother, her family and health professionals. If born alive, these babies would either not survive or would have significant disability.

Avoiding the ethical and emotional consequences of signs of life at the time of delivery is a widely

\section{CORRESPONDENCE}

Dr Beemba Shakya

Department of Obstetrics and Gynaecology

Paropakar Maternity and Women's Hospital, Thapathali, Kathmandu, Nepal.

Email: docbeemba@yahoo.com

Phone: +977-9841 729847 recognized benefit of fetal demise before induction termination. ${ }^{2,3}$ Intracardiac potassium chloride is used most often to induce fetal demise in developed countries. $^{4-7}$ Alternatively, intra-amniotic digoxin instillation under ultrasound guidance can be used to induce fetal demise in low resource countries as relatively simple technology.

The objective of this study was to induce fetal demise before termination of pregnancy by instillation of digoxin intra-amniotically for fetal anomaly in second and early third trimester.

\section{METHODS}

This was a cross-sectional study undertaken at Paropakar Maternity and Women's Hospital from April 13, 2012 to October 13, 2013. Ethical approval was obtained from the hospital. Patient characteristics, gestational age, types of fetal anomaly and its time of detection were recorded in 32 cases with fetal anomaly in second and early 
third trimester after taking informed consent from the patients. With aseptic precautions under ultrasound guidance, one milligram digoxin was instilled intraamniotically by 22-gauze spinal needle and after 24 hours, ultrasonography was repeated to check for fetal cardiac activity. Induction of labour using misoprostol as per FIGO guideline was used. For gestational age 18-26 weeks', misoprostol 100 microgram (mcg) per vaginally $(\mathrm{P} / \mathrm{V}) 6$ hourly maximum 4 doses and for 27-43 weeks' of gestation, 25-50 mcg P/V 4 hourly maximum 6 doses were used. ${ }^{8,9}$ Augmentation with oxytocin was done if already in labour. Induction to delivery interval, effectiveness and side effects of digoxin were recorded.

\section{RESULTS}

Among 32 cases of fetal anomaly, majority occurred in primigravida $(\mathrm{n}=17,53.12 \%)$. The mean age was 25 years (range: 18-33 years) and mean gestational age 26.5 weeks (range: 20-34 weeks) (Table 1).

Table 1. Characteristics of the patients $(n=32)$.

\begin{tabular}{|c|c|}
\hline Age (years) & Number $(\%)$ \\
\hline $18-19$ & $3(9.37)$ \\
\hline $20-24$ & $12(37.5)$ \\
\hline $25-29$ & $9(28.12)$ \\
\hline $30-34$ & $8(25)$ \\
\hline \multicolumn{2}{|l|}{ Gravidity } \\
\hline Primi & $17(53.12)$ \\
\hline $\mathrm{G}_{2}$ & $9(28.12)$ \\
\hline $\mathrm{G}_{3}$ & $3(9.37)$ \\
\hline $\mathrm{G}_{4}$ & $3(9.37)$ \\
\hline \multicolumn{2}{|c|}{ Gestational age (weeks') } \\
\hline $20-24$ & $16(50)$ \\
\hline $25-29$ & $7(21.87)$ \\
\hline $30-34$ & $9(28.12)$ \\
\hline
\end{tabular}

Table 2. Fetal anomaly $(n=32)$.

\begin{tabular}{ll}
\hline Fetal anomaly & Number $(\%)$ \\
\hline Anencephaly & $16(50)$ \\
Multiple & $6(18.75)$ \\
Hydrocephalus & $2(6.25)$ \\
Cystic hygroma & $2(6.25)$ \\
Neural tube defect & $2(6.25)$ \\
Hydrops fetalis & $1(3.12)$ \\
Esophageal atresia & $1(3.12)$ \\
Polycystic kidneys & $1(3.12)$ \\
Rhizomelia & $1(3.12)$ \\
\hline
\end{tabular}

Thirty one (96.87\%) cases visited out-patient department (OPD) and one case (3.12\%) visited emergency room with prelabour rupture of membrane at 34 weeks' gestation.

Table 3. Fetal anomaly detection in OPD $(n=31)$.

\begin{tabular}{ll}
\hline Period of gestation (weeks') & Number (\%) \\
\hline $20-24$ & $16(50)$ \\
$25-29$ & $7(21.87)$ \\
$30-34$ & $8(25)$ \\
\hline
\end{tabular}

Following 24 hours of intra-amniotic Digoxin, cardiac activity was absent in $100 \%$ and there was no side-effect of Digoxin.

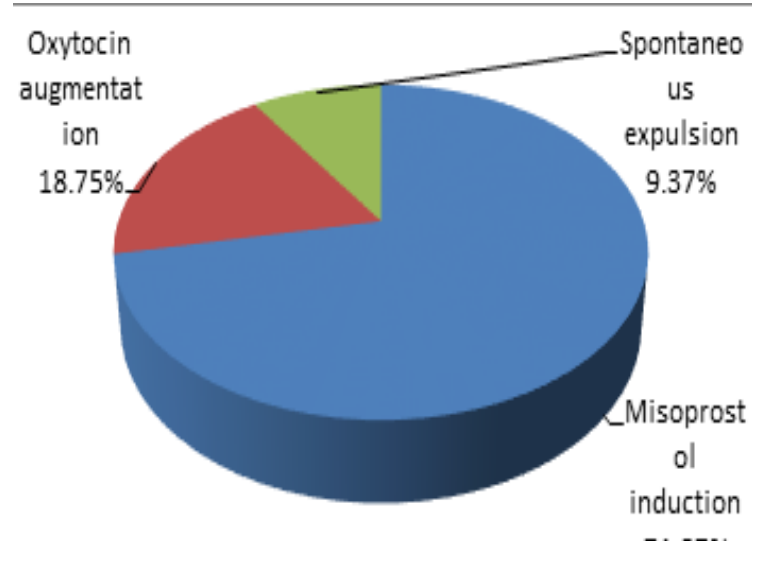

Figure 1. Facilitation of expulsion $(n=32)$.

The mean induction to delivery interval was 47.3 hours (Figure 2).

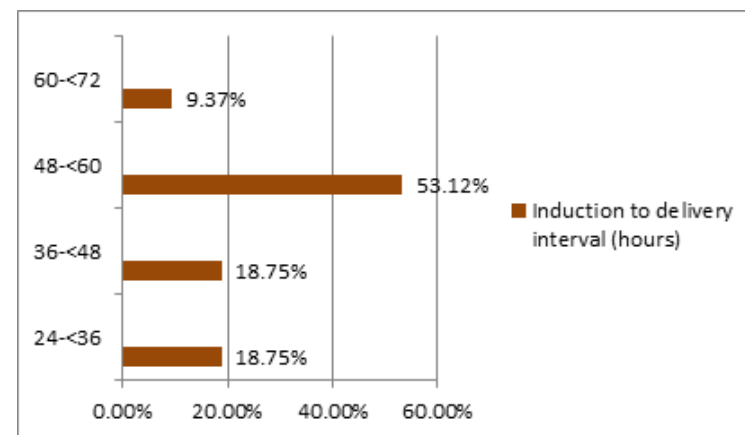

Figure 2. Induction to delivery interval $(n=32)$.

\section{DISCUSSION}

In this study, mean gestational age was 26.5 weeks' ranging from 20-34 weeks'. In a study conducted by Hern et al, ${ }^{10}$ gestational lengths ranged from 15-34 weeks' for a variety of chromosomal abnormalities and malformations. The most common fetal anomaly 
was neural tube or central nervous system defects (27\%) and trisomy 21 (24\%). In our study, 50\% of fetal anomaly was anencephaly and $18.75 \%$ with multiple fetal anomaly (Table 1).

In one of the studies, gestational age ranged from 20-23 weeks' of gestation. ${ }^{11}$ In various other studies, gestational age ranged from 17-24 weeks' of gestation. ${ }^{12-14}$ In our study, although almost all the cases had visited OPD (96.87\%), unfortunately, 25\% of them presented late at 30-34 weeks' of gestation.

In a study by Nucatola $\mathrm{D}$ et al ${ }^{12}$ where 52 women at 18-24 weeks' gestation were randomized to one of four digoxin groups; doses of 1 and $1.5 \mathrm{mg}$ either instilled intra-amniotically or intrafetally. The failure rate did not vary by route of administration nor lowered by increasing the dose from 1-1.5mg. Hence, they concluded both the routes are safe and effective and doses of more than $1 \mathrm{mg}$ may not be necessary.

In this study, following 24 hours of intra-amniotic digoxin, cardiac activity was absent in 100\%. This is comparable to a study by Borgatta et al, ${ }^{15}$ which concluded intra-amniotic injection of digoxin $1.5 \mathrm{mg}$ is effective at causing fetal demise by 20 to 24 hours.

In a trial by Jackson et al, ${ }^{11} 126$ women were randomized to receive either $1 \mathrm{mg}$ intra-amniotic digoxin $(n=62)$ or placebo $(n=64)$. At 24 hours, there was a failure rate of $8 \%$. In another study, digoxin effectively induced fetal death in $87 \%$ of women. ${ }^{12}$ In 2001, in a large series of 1677 consecutive patients, intrafetal digoxin injections of 1.5-2 mg reported no failures of causing demise. ${ }^{16} \mathrm{~A}$ retrospective cohort analysis by Molaei et $\mathrm{al}^{14}$ assessed varying doses of intrafetal digoxin and reported no failure to induce demise at a $1 \mathrm{mg}$ dose among 107 patients.

Intra-amniotic digoxin has been noted to induce labour leading to abortion over the course of 2-3 days. ${ }^{11}$ However, in our protocol, if there was no initiation of labour within 24 hours of intra-amniotic digoxin, misoprostol induction as per FIGO guideline was done (Figure 1). The majority of the cases $(53.12 \%)$ expelled within 48-60 hours; mean induction to delivery interval was 47.3 hours.

In the present study, there was no adverse effect of digoxin. In a pharmacokinetic study by Drey EA et al, ${ }^{17}$ for the safety of $1 \mathrm{mg}$ intra-amniotic digoxin, women had a Holter monitor placed one hour before their digoxin injection and wore it for 24 hours until their dilatation and evacuation. No clinical significant cardiac events or digoxin related arrhythmias were noted. Similarly, some studies also reported no complications and signs of toxicity or clinically significant cardiac events. ${ }^{14,16}$

\section{CONCLUSIONS}

Intra-amniotic Digoxin instillation appeared safe and effective in inducing fetal demise for fetal anomaly in second and early third trimester. However, this study was limited due to small sample size and larger study is required to come to any concrete conclusion.

\section{DISCLOSURE}

The authors report no conflicts of interest in this work.

No violation of human rights and safety.

Funding: Nil

\section{REFERENCES}

1. Gliozheni O, Sylejmani S, Kati K. Ultrasound and diagnosis of fetal anomalies. Donald School of Ultrasound in Obstetrics and Gynecology. 2011;5(3):193-204.

2. Isada NB, Fletcher JC, Pryde PG, Johnson MP, Evans MI. Fetal intra-cardiac potassium chloride injection to avoid the hopeless resuscitation of an abnormal abortus: I. Clinical issues. Obstet Gynecol. 1992;80:296-9.

3. Fletcher JC, Isada NB, Pryde PG, Johnson MP, Evans MI. Fetal intracardiac potassium chloride injection to avoid the hopeless resuscitation of an abnormal abortus: II. Ethical issues. Obstet Gynecol. 1992;80:310-3.

4. Bhide A, Sairam S, Hollis B, Thilaganathan B. Comparison of feticide carried out by cordocentesis versus cardiac puncture. Ultrasound Obstet Gynecol. 2002;20:230-2.

5. Eddleman KA, Stone JL, Lynch L, Berkowitz RL. Selective termination of anomalous fetuses in multifetal pregnancies: two hundred cases at a single center. Am J Obstet Gynecol. 2002;187:1168-72.

6. Hern WM. Selective termination for fetal anomaly/genetic disorder in twin pregnancy at 32+ menstrual weeks: report of four cases. Fetal Diagn Ther. 2004;19:292-5.

7. Pasquini L, Pontello V, Kumar S. Intracardiac injection of potassium chloride as method for feticide: experience from a single UK tertiary centre. BJOG. 2008;115:528-31.

8. Ponce de Leon RG, Wing D, Fiala C. Misoprostol for intrauterine fetal death. International Journal of Obstetrics and Gynecology. 2007;99:190-3.

9. WHO recommendations for induction of labour. Geneva World Health Organization; 2011.

10. Hern WM, Zen C, Ferquson KA, Hart V, Haseman MV Outpatient abortion for aetal anomaly and fetal death from 15-34 menstrual weeks' gestation: techniques and clinical management. Obstet Gynecol. 1993;81(2):301-6. 
11. Jackson RA, Teplin VL, Drey EA, Thomas LJ, Darney PD. Digoxin to facilitate late second trimester abortion: a randomized, masked, placebo-controlled trial. Obstet Gynecol. 2001;97:471-6.

12. Nucatola D, Roth N, Gatter M. A randomized pilot study on the effectiveness and side-effect profiles of two doses of digoxin as fetocide when administered intraamniotically or intrafetally prior to second-trimester surgical abortion. Contraception. 2010;81(1):67-74.

13. Gariepy AM, Chen BA, Hohmann HL, Achilles SL, Russo JA, Creinin MD. Transvaginal administration of intraamniotic digoxin prior to dilation and evacuation. Contraception. 2013;87(1):76-80.

14. Molaei M, Jones HE, Weiselberg T. McManama M, Bassell $\mathrm{J}$, Westhoff CL. Effectiveness and safety of digoxin to induce fetal demise prior to second- trimester abortion. Contraception. 2008;77:223-5.

15. Borgatta L, Betstadt SJ, Reed A, Feng KT. Relationship of intra-amniotic digoxin to fetal demise. Contraception. 2010;81(4):328-30.

16. Hern WM. Laminaria, induced fetal demise and misoprostol in late abortion. Int J Gynaecol Obstet. 2001;75:279-86.

17. Drey EA, Thomas LJ, Benowitz NL, Goldschlager N, Darney PD. Safety of intra-amniotic digoxin administration before late second-trimester abortion by dilation and evacuation. Am J Obstet Gynecol. 2000;182:1063-6. 